\title{
O CANDOMBLÉ EM SÃo PAULO E A SACRALIZAÇÃO DO ESPAÇO URBANO
}

Vagner Gonçalves da Silva*

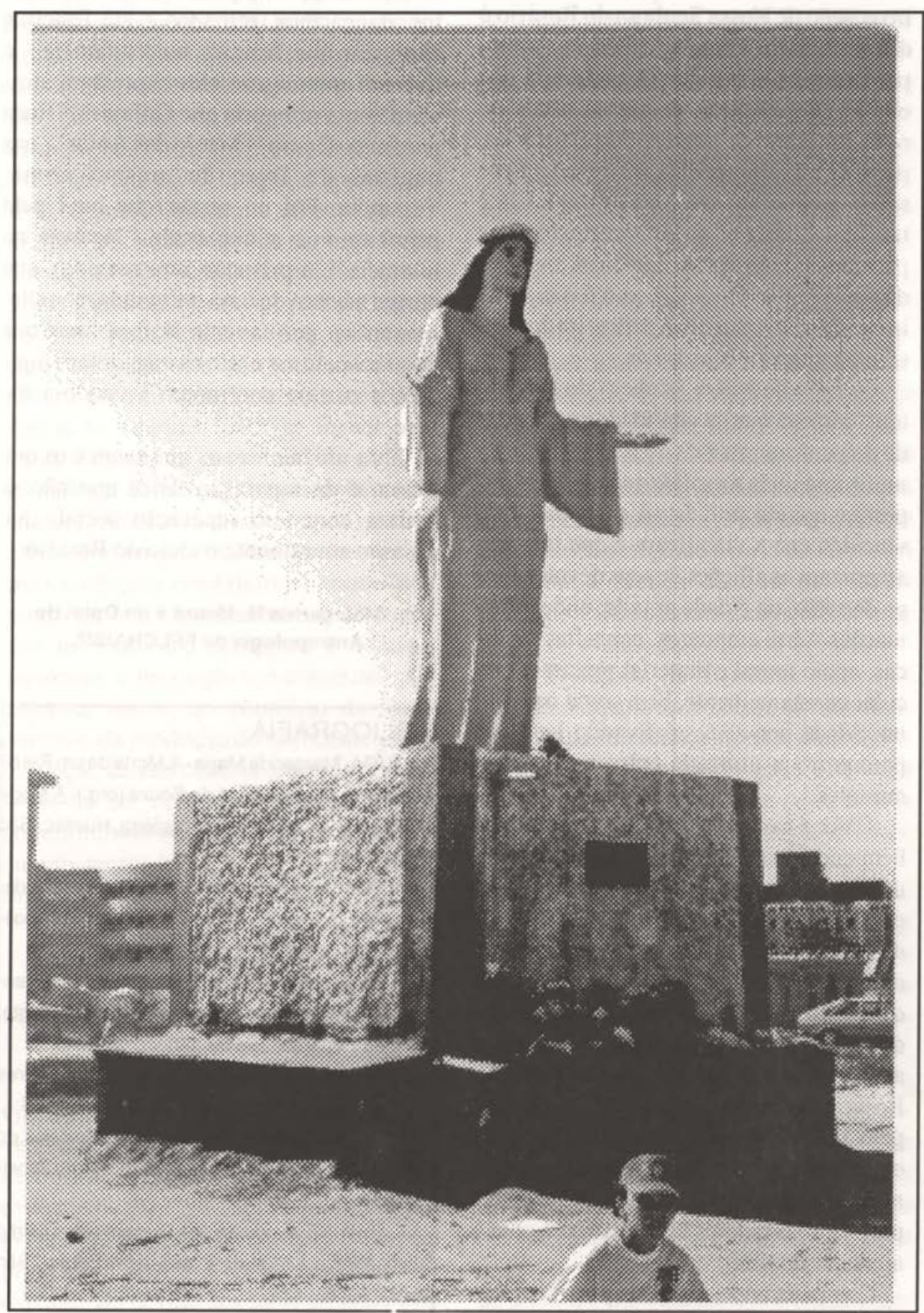

Foto: Vagner Gonçalves da Silva

\section{MIGRAÇÃO E FORMAÇÃO DO CANDOMBLÉ EM SÃO PAULO}

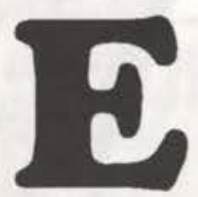

ntre os fatores do crescimento do número de terreiros de candomblé, verificado a partir dos anos 60 em São Paulo, está a imigração de populações nordestinas que nesse período é intensa. Os adeptos vieram de regiões onde essa religião teve um desenvolvimento maior, como o Nordeste e posteriormente o Rio de Janeiro, em busca de melhores condições de vida. Chegando aqui principalmente para trabalhar, muitos deram continuidade à sua história de vida religiosa fazendo da reconstituição das "familias-de-santo" e das "nações" religiosas uma importante estratégia de sobrevivência sob as novas condições de vida na metrópole.(1)

\section{"FAMÍLIAS -DE-SANTO"}

Entre as principais "nações" que se expandiram em São Paulo com a vinda dos imigrantes estão o angola, $o$ efã e queto ("nações" predominantes nas cidades da Bahia), o xangô de Pernambuco, o xambá de Alagoas, otambor de mina maranhense e agora, inclusive, o batuque gaúcho, marcando as migrações sociais e religiosas também no sentido sul-sudeste. Da "nação" angola um dos nomes mais lembrados pelo povo-de-santo que deu continuidade aqui à sua família religiosa é o de Pai Joãozinho da Goméia (João Torres Filho), baiano de origem, que por volta dos anos 50 se estabeleceu no Rio de Janeiro e através de frequentes viagens a São Paulo iniciou grande quantidade de filhos. São 
também desta "nação" os descendentes paulistas de Nanã de Aracaju (Erundina Nobre Santos, famosa mãe-de-santo desta cidade), como Mãe Manodê que se estabeleceu na Vila Brasilândia, em São Paulo, sendo seu terreiro provavelmente o primeiro a ser registrado como de candomblé, nos anos 60. Da "nação"' efã, fundada em Salvador por africanos (Maria da Paixão e seu esposo Olufandeí) vieram seus descendentes de terceira geração para o Rio de Janeiro como Cristóvão de Ogum, cujosfilhos-de-santo Waldomirode Xangô e Álvaro de Omolu trouxeram este rito para São Paulo

Na trilha aberta pelo efã, a "nação" queto (da qual fazem parte terreiros nacionalmente conhecidos como o Gantois e o OpôAfonjá, ambos de Salvador) foi trazida, entre outros, por Seu Nezinho de Ogum, proveniente de Muritiba, cidade do Recôncavo Baiano. Pai Nezinho, nos anos 60 e 70, vinha frequentemente a São Paulo para iniciar pessoas na religião e passar seus conhecimentos aos já iniciados. Sua filha carnal Juju de Oxum, uma das mais antigas iniciadas de São Paulo continua a herança religiosa de Pai Nezinho em seu terreiro localizadoem Sapopemba, naZona Leste.

Da "nação" jêje, na sua variável maranhense, chamada tambor-de-mina, veio o paraense Francelino de Xapanã. Pioneiro desta "nação" em São Paulo o terreiro de Pai Francelino, fundado há mais de dezanos no município de Diadema, na Grande São Paulo, abriga o culto aos voduns e "encantados", entidades muito populares no Pará e Maranhão.

O candomblé em São Paulo não se formou, contudo, apenas pelo transposição das "famílias-de-santo", e das "nações" de outros locais para cá, sem choques ou impedimentos. Para a mãe-desanto Zefinha de Oxum, por exemplo, que veio do Recife para São Paulo acompanhando seu marido em 1951, a migração geográfica também significou migração religiosa do candomblé para a umbanda. Iniciada no xangô pernambucano (variação regional do rito queto), Mãe Zefinha, aqui, abriu seu terreiro (de umbanda) em 1960, numa época em que esta religião era melhor aceita que o candomblé. Contrariamente, para seu irmão-de-santo José de Oxalá, que no início dos anos 80 veio de Recife para São Paulo (a princípio em

\section{Exemplo de "família-de-santo" \\ e migração religiosa:}

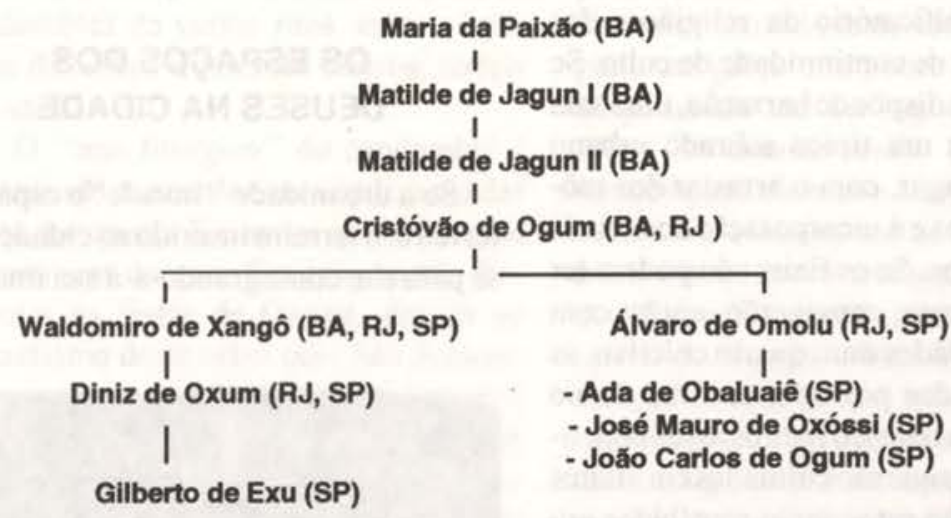

busca de melhores condições de vida) a migração geográfica significou a possibilidade de expansão de sua "família-desanto" que havia permanecido no Recife. Em 1984, José patrocinou a vinda de sua mãe-de-santo, Das Dores (respeitada figura do culto pernambucano), e do seu terreiro. A mudança deste (dos objetos rituais, assentamento dos orixás etc.), realizada por avião, ilustra bem as transformações ocorridas no campo religioso afro-brasileiro de São Paulo que a partir dos anos 70 já é considerado propício para sediar terreiros antigose famosos, garantindo, aqui, a continuidade destes, muitas vezes ameaçada (por motivos financeiros e outros) em suas terras de origem.

\section{A SACRALIZAÇÃO DOS ESPAÇOS URBANOS}

Sendo o condomblé uma religião mágica, sacrificial e de culto a deuses que representam as forças da natureza, seu desenvolvimentona metrópole (espaço tipo por excelência como o dos processos de racionalização, urbanização e industrialização) realiza-se como resultado de negociações entre a esfera religiosa e as outras que se lhe opõem. Ao sacralizar o terreiro e a cidade, o candomblé sinaliza um espaço físico e social com seus símbolos religiosos e sua forma peculiar de ver o mundo.

\section{OS ESPAÇOS DOS DEUSES NO TERREIRO}

No candomblé o terreiro é a sede do axé (força sagrada). É nele que se encontram os altares e objetos sagrados e estão plantados (enterrados, muitas vezes) os "fundamentos" dos orixás. É, portanto, através do modo como o espaço profano se torna sagrado que se compreende a visão de mundo estabelecida pela religião.

Imaginando um gradiente que vai do menos ao mais sagrado os "espaços menos sagrados" do terreiro são os constituídos pelos cômodos ou lugares cujo acesso é permitido a todos, como o barracão: lugar onde se realizam as festas e os toques públicos.

A estes somam-se os "espaços mais sagrados", depositários das coisas do axé, cujo acesso é permitido somente aos iniciados, como o roncó: quarto de feitura, onde são realizados os rituais mais secretos da religião (como as iniciações); o pejí: local onde ficam os assentamentos dos orixás cultuados, em forma de altar coletivo ou que, dependendo das dimensões do terreiro, poderá ser constituído por altares separados (para cada deus) no interior de pequenos cômodos; o quarto de Exu: local de veneração a este deus que, sendo considerado agente mensageiroe intermediário entre os homens e os orixás, deve ter seu altar separado dos demais; o quarto de Balé: onde se encontram assentados os eguns da casa, espíritos dos mortos, e os altares externos: locais onde são "plantados" os assentamentos de certas divindades que não podem ser cultuadas em recintos fechados como o Exu da casa cujo assentamento em geral deve ficar ao lado do portão principal do terreiro para protegê-lo. 
Nos casos onde em poucos metros quadrados ocorrem os rituais e se alojam as representações materiais dos deuses, prescrições são reinterpretadas a partir do sistema classificatório da religião e das necessidades de continuidade do culto. Se o terreiro não dispõe de barracão, uma sala de visitas de um típico sobrado urbano poderá dar lugar, com o arrastar dos móveis, às danças eà incorporação dos orixás nos seus filhos. Se os Exus não podem ter sua própria casa, conviverão, então, com outras divindades num quarto coletivo, às vezes separados por uma cortina. Se no tefŕeiro não há espaço para os assentamentos dos deuses que são cultuadosem altares externos então estes serão recolhidos em um quarto; e se, ai, nem todos os deuses podem ficar no chão, de onde provém a força vital que garante o dinamismo do sistema cosmológico, serão então dispostos em prateleiras seguindo, contudo, certas regras: os orixás mais "quentes", relacionados com o fogo ou a terra (como Ogum, Xangô e Obaluaiê), ocuparão as posições, na prateleira, mas próximas ao solo; já os orixás mais "frios" relacionados com a água e o ar (como Oxum, Iemanjá e Oxalá), ficarão nas posições altas. Exu, guardião das fronteiras ficará sempre próximo à porta do peji e isto acabará por reproduzir, mesmo num único cômodo, todas as representações simbólicas relevantes do sistema religioso do terreiro.

Por outro lado, devido ao sucesso da carreira sacerdotal dos pais-de-santo ou às boas condições financeiras anteriores, proliferam em São Paulo terreiros instalados em amplas dependências, construídas ou adaptadas para satisfazer todas as necessidades do culto, ou para atender também uma certa "sofisticação" e exigência de conforto e de estilo próprios do mundo moderno e absorvidos pelo grupo religioso.

Assim, em São Paulo, é comum que os orixás sejam cultuados tanto em pequenos apartamentos, em conjugados, cortiços, fundos de garagem, velhos casarões italianos no Bixiga, ao lado de restaurantes chineses na Liberdade, ou ainda em majestosas casas nos bairros nobres da cidade como nos Jardins, Alto da Lapa etc. E há também aqueles terreiros construídos para o culto dos orixás em áreas menos urbanizadas, mas afastadas do perimetro urbano, com uma "natureza mais intacta", próprias ao culto aos orixás, como Cotia, Taboão da Serra etc.

\section{OS ESPAÇOS DOS DEUSES NA CIDADE}

Se a urbanidade "invade" o espaço do terreiro, o terreiro inserido na cidade abrese para ela, consagrando-a à sua imagem, habitando-a com os deuses cujo culto traz como dinâmica religiosa peculiar a sacralização dos elementos naturais, como montanhas, rios, mar, árvores e florestas. Pois se orixá é também natureza, seu axé encontra-se e renova-se na água, terra e folhas que the são consagradas. Muitos dos rituais da religião devem ser, portanto, realizados além dos muros dos terreiros, em pontos onde se acredita estar a fonte de energia mítica dos deuses.

As manifestações nas praias das cida-

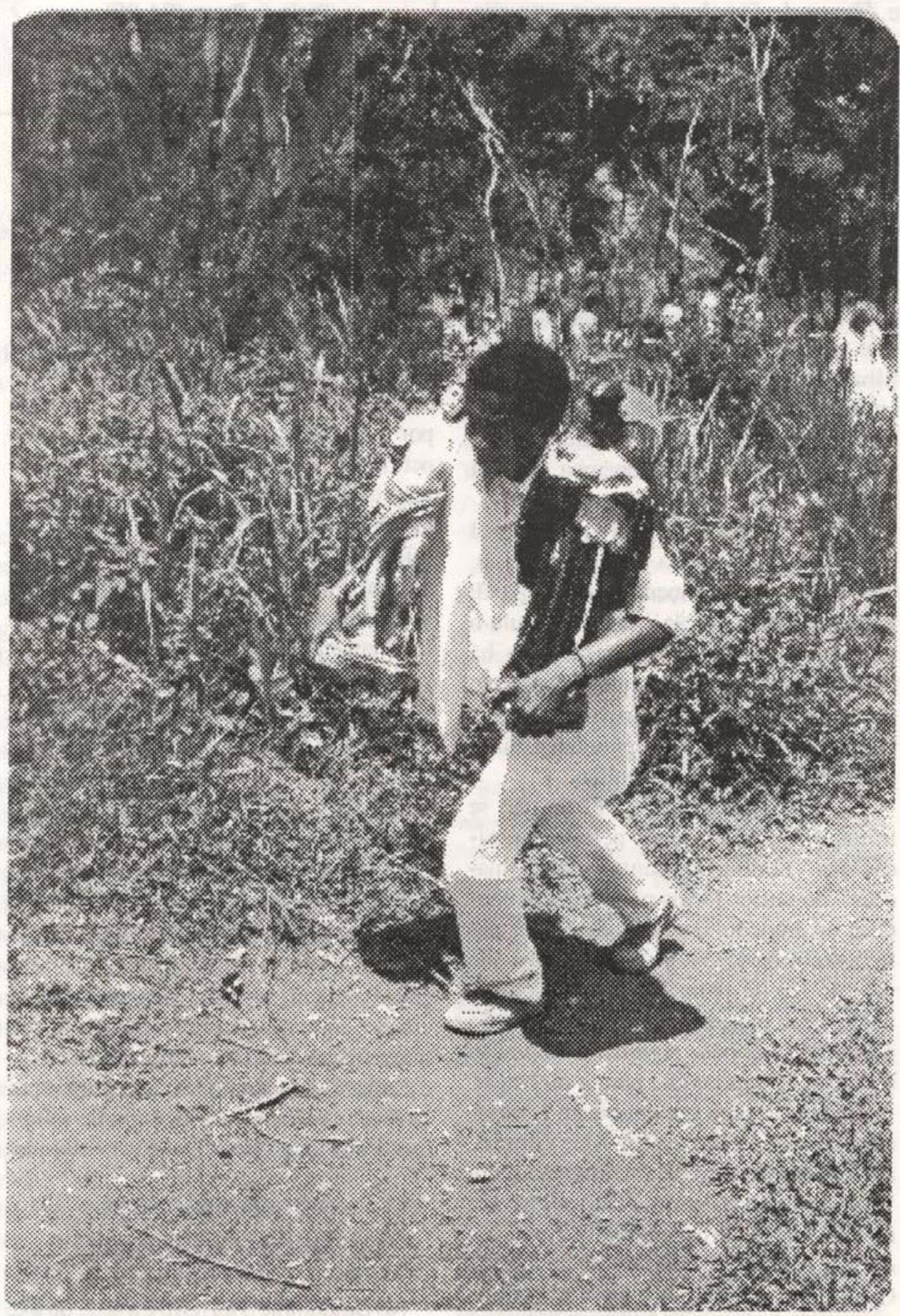

Foto: Vagner Gonçalves da Silva 
des litorâneas brasileiras em louvor a Iemanjá, rainha do mar, devido à sua popularidade foram, no processo de ocupação, sacralização "institucionalização" dos espaços naturais da cidade, as que mais visibilidade trouxeramàs religiões afro-brasileiras fora dos espaços dos terreiros. Cultuada em torno do dia 8 de dezembro, em São Paulo, tem sua festa realizada, desde os anos 60 , na Praia Grande, consolidando-se cada vez mais como expressão legítima da cultura religiosa popular sendo, inclusive, atualmente patrocinada pelos órgãos de turismo municipal e estadual.

As oferendas para Oxum (deusa da água doce) nos lagos, cachoeiras, represas ou em áreas de mananciais denota, também, a apropriação simbólica do espaço urbano pela religião. E não é de se estranhar que até em pequenos córregos que cortam a cidade ou mesmo em lagos como o do Ibirapuera possamos encontrar oferendas a esta vaidosa deusa do amor.

Outro importante deus a habitar os espaços da cidade é Exu, deus da comunicação que recebe seus despachos nas avenidas da cidade. Em geral a entrega dos ebós de Exu realizam-se nas encruzilhadas por volta da meia-noite, seja porque neste horário evidencia-se a transformação ou o limite entre o dia que finda e o outro que se inicia ou porque as ruas da cidade tornam-se menos movimentadas. Mas devem ser encruzilhadas em forma de " $\mathrm{X}$ " (cruzamento de duas ruas), porque aquelas em forma de " $\mathrm{T}$ "' (encontro perpendicular de duas ruas) sãode Pombagira, qualidade feminina de Exu, muito solicitada para resolver problemas amorosos ou sexuais. A champagne, cigarros e flores vermelhas são suas principais oferendas.

\section{O TERREIRO E A CIDADE: NA ENCRUZILHADA DOS HOMENS E DOS DEUSES}

A formação do candomblé em São Paulo é largamente tributária da imigração nordestina que a partir dos anos 60 marcou a vinda das inúmeras "famíliasde-santo" e "nações" que compõem esta religião.

O candomblé aqui teve que se estabelecer dialogando no interior de um campo religioso no qual a umbanda, majoritária e mais antiga, a princípio recebeu muitos dos seus adeptos. Num segundo momento, já melhor compreendido e aceito socialmente, o candomblé se desenvolveu a partir da passagem de umbandistas para os seus quadros, das novas levas de imigrantes iniciados (ou que se iniciaram aqui) e da progressiva conversão dos paulistas.

Inserido na metrópole, as práticas rituais do candomblé vêm se reproduzindo através do diálogo com as condições do meio urbano, seja nos espaços físicos propriamente ditos, da cidade, como praças, praias e encruzilhadas, nos "espaços"' dos meios de comunicação como rádio, televisão, jornais e revistas, e nos "espaços" do circuito cultural urbano como teatros, museus etc., onde formas de expressão artística (musical, iconográfica, dramática, coreográfica etc.), inspiradas na temática religiosa afro-brasileira, são alaboradas e divulgadas como parte constitutiva e legítima da cultura brasileira.

Assim, se o espaço da cidade passa a ser pensado como parte integrante do cosmos do candomblé (uma extensão do domínio do terreiro) é porque ele não se apresenta aos olhos do fiel apenas como o lugar (profano) da convivência dos homens entre si, provenientes dos mais variados pontos, mas também dos deuses invocados pelos homens nos momentos de sucesso ou aflição. Porque os orixás, como dizo povode-santo, estão e atuam onde os homens estão e atuam. E ao ser praticado por gente de todas as procedências, origem, cor, classe e status social, acomodando ritos e construindo significados "novos", o candomblé mostra-se como religião dinâmica em diálogo com o mundo no qual se insere. E neste diálogo entre o candomblé e a cidade, a incorporação de termos de um universo pelo outro permite que os deuses (e os seus ritos), se transformem para habitar a cidade (como espaço físico e social) e que esta se faça cada vez mais apropriada para recebê-los e protegê-los como parte integrante do seu amplo mercado de "bens simbólicos". Se os orixás "migram" acompanhando e marcando com seus símbolos o percurso dos seus filhos é porque a religião continua sendo uma forma importante de atuação no mundo do qual se vem ou no qual se está.
* Vagner G. daSilvaé antropólogo pela FFLCH daUSP, com pesquisa sobre o candomblé em Săo Paulo, financiada pelo CNPq/FAPESP.

\section{NOTA}

1- "Famílias-de-santo" designa no candomblé um grupo de adeptos que têm relações de parentesco mítico estabelecido principalmente através da iniciação. Uma vez iniciada, a pessoa torna-se filha-desanto de seu iniciador, isto é, do seu de agora em diante pai ou mãe-de-santo e terá na comunidade religiosa irmãos, primos, tios, avôs etc. "no santo", O termo "nação" , embora faça alusão aos grupos étnicos dos escravos africanos trazidos para o Brasil como os bantos, nagôs etc., designa muito mais uma forma (modalidade) de rito em torno da qual as "famílias-desanto" estabelecem sua identidade religiosa.

\section{BIBLIOGRAFIA}

\section{- BASTIDE, Roger -}

As Religiões Africanas no Brasil. Săo Paulo. Pioneira, 1971

- CONCONE, Maria Helena V. B. \& NEGRÁO, Lisias N. - "Umbanda: da Representaçăo à Cooptaçăo. In: Umbanda ePolitica. Rio de Janeiro, Marco Zero, Cadernos do ISER (18): $43-80$, 1985.

- ELIADE, Mircea - O Sagrado e o Profano. Ed. Livros do Brasil, Lisboa.

- GONÇALVES DA SILVA, Vagner Candomblé na Cidade. Tradição e Renovaçāo. Săo Paulo, FFLCH/USP, (mimeo), 1992.

- LIMA, Vivaldo da Costa -

A Familia-de-Santo dos Candomblés JejêNagós da Bahia. Salvador. UFBA.

- PRANDI, Reginaldo - Os Candomblés de São Paulo. Sáo Paulo, Hucitec/EDUSP, 1991.

-PRANDI, Reginaldo\& GONÇALVESDA SILVA, Vagner - "Axé Săo Paulo". In: MOURA, Carlos E. M. de (org.) Meu Sinal Está em Teu Corpo. Săo Paulo, EDICON/EDUSP, 1989. 